\title{
Revisando o passado e construindo o presente: o movimento gay como espaço educativo*
}

\author{
Anderson Ferrari
}

Universidade Federal de Juiz de Fora, Colégio de Aplicação João XIII

\section{Introdução}

O movimento gay começou a se organizar entre o final da década de 1970 e o início dos anos de 1980. Não somente o movimento gay, mas outros grupos sociais, nesta época, articulavam-se pela defesa da visibilidade, pela construção de novas formas de conhecimento, de cidadania plena e pela luta por direitos civis. Essas reivindicações demonstravam a importância do contexto político em que se desenvolviam. $\mathrm{O}$ fim da ditadura militar fazia surgir e reforçava um sentimento de otimismo cultural e social que atingia a todos. A abertura política possibilitava sonhar com uma sociedade mais democrática, igualitária e justa e, mais especificamente, trazia a esperança para o movimento gay de uma sociedade em que a homossexualidade poderia ser celebrada sem restrições. Havia a consciência de que a luta era árdua e que passava pela

* Trabalho apresentado no GT Movimentos Sociais e Educação, durante a $26^{\mathrm{a}}$ Reunião Anual da ANPEd, realizada em Poços de Caldas, MG, de 5 a 8 de outubro de 2003. desconstrução dos parâmetros da homossexualidade, com seus conseqüentes tabus, e pela construção de identidades mais positivas, embasadas na valorização da auto-estima, da auto-imagem e do autoconceito ${ }^{1}$ de seus integrantes.

Autores como Fry e MacRae (1985), MacRae (1990) e Green (2000) vêm desenvolvendo pesquisas enfocadas na homossexualidade, com destaque para o surgimento, desenvolvimento e continuidade do movimento gay no Brasil, ressaltando que uma das maiores dificuldades enfrentadas é a falta de conhecimento das formas de controle social que caracteriza a sociedade brasileira. Muda, assim, o foco das preocupações: o objeto da luta não é a repressão, mas a cultura brasileira.

Mesmo concentrando o foco na cultura brasileira, os movimentos tiveram ou buscaram influência

${ }^{1}$ As noções de auto-estima, auto-imagem e autoconceito estão embasadas em Oliveira (1994), que analisa como elas contribuem para a elaboração das identidades das pessoas, na medida em que buscam repensar o pré-construído, os pré-conceitos responsáveis pela cristalização das imagens entendidas como naturais. 
em outros países. A inspiração veio das lutas empreendidas pelos movimentos da contracultura, originários da Inglaterra e dos Estados Unidos. Na medida em que era crescente o desinteresse pela forma como a política era conduzida, aumentavam as preocupações com o desejo, o erotismo, a intimidade, o corpo, a subversão de valores e comportamentos. Esses dois aspectos que se complementam, ou seja, a influência dos movimentos da contracultura e os novos interesses, serviram de terreno fértil para o nascimento do movimento gay.

O resultado foi a vivência de um período de efervescência da homossexualidade. Talvez se possa explicar esse boom pelo próprio contexto da década de 1970, em que a glorificação da marginalidade era um aspecto que atingia a cultura brasileira. Mas o que importa nesse aspecto é o seu desdobramento: a crescente visibilidade das práticas homossexuais, a descoberta desse novo público pelos setores comerciais e o surgimento de uma moderna subcultura gay. Ou seja, o que estava em construção era uma alteração na relação entre homossexualidade e sociedade, que colocava desafios para o grupo. MacRae (1990) define com clareza a dupla alteração que motivava os grupos de militância gay: elaborar "novas formas de representação do homossexual na sociedade, através de grupos de reflexão"; e, também, "difundir pelo resto da sociedade os novos valores criados" (p. 33-34). Passados mais de 20 anos desde o surgimento dos primeiros grupos gays no Brasil, esses desafios ainda estão presentes e compõem a pauta de discussão das reuniões. A fala de um integrante do movimento gay é reveladora:

O movimento homossexual, eu diria, mundial [...]. A gente não parte do zero, a gente parte do negativo. Todo mundo compra um lotezinho e ergue um prédio. A gente que é bicha, não. A gente compra um lotezinho, mas tem um casebre lá. Então, nós temos que destruir esse casebre, limpar esse terreno, melhorar a fundação para depois construir. ${ }^{2}$

${ }^{2}$ Depoimento de um dirigente do Movimento Gay de Minas (MGM), Juiz de Fora (29/1/03).
O movimento gay teve um novo desenvolvimento no mundo e no Brasil, principalmente após o advento da AIDS. Hoje já somam grupos organizados em todas as regiões do Brasil. A princípio, esse fato parece demonstrar a vivência de uma nova economia sexual, talvez diferente de tudo que até então havia dominado a sexualidade, sobretudo as práticas homoeróticas: vergonha, silêncio, repressão, censura, discriminação e preconceito. A multiplicação dos movimentos gays organizados estaria evidenciando uma nova postura dos homossexuais e, consequientemente, uma nova relação entre cultura, sociedade e indivíduos. Essas afirmações preliminares, baseadas numa visão despretensiosa, inocente e aparente, são constantemente utilizadas para os mais variados fins: para "acalentar" o movimento gay e com isso mantê-lo onde está, para argumentar contra os avanços conseguidos, e também para satisfazer, ilusoriamente, alguns homossexuais receosos de sustentar a luta.

Por tudo isso, o movimento gay vem constituindo-se como um espaço de extrema importância na luta por direitos, por visibilidade, por emancipação e por justiça, no melhor exemplo do que Boaventura Santos classifica de globalização alternativa ou periférica. ${ }^{3}$ Nascida em meio a um contexto político específico, essa luta foi capaz de se renovar incorporando novas reivindicações e buscando novos mecanismos de luta. Nessa renovação, foi inserida a preocupação com a educação mais formal, sobretudo após a epidemia da AIDS, que em seu início atingiu, sobremaneira, a comunidade homossexual masculina, sendo apelidada até mesmo de "câncer gay". Ante a exigência de se organizar contra a doença, os movimentos gays reafirmaram a importância da educação como a melhor arma nessa guerra sem tréguas, dando origem a diferentes cursos de prevenção de Doenças Sexual-

\footnotetext{
${ }^{3}$ Como define Santos (2002), a globalização alternativa é
} aquela "constituída pelas redes e alianças transfronteiriças entre movimentos, lutas e organizações locais ou nacionais que nos diferentes cantos do globo se mobilizam para lutar contra a exclusão social" (p. 13). 
mente Transmissíveis (DST)/AIDS, assim como trabalhos e projetos de assistência a pessoas infectadas pelo HIV. Hoje, esses trabalhos vão além da assistência e do atendimento aos membros dos grupos. Para citar apenas um exemplo, não é difícil encontrar a ação dos grupos no interior das escolas por meio de palestras, debates e oficinas a respeito das diferenças, homossexualidades e prevenção DST/AIDS.

Dessa forma, foi fortalecendo-se uma característica que já existia no interior do movimento gay desde o seu surgimento: a dedicação à educação. A referência não é à educação escolarizada, mas a todo processo educacional mais amplo, à essência da educação. O objetivo do movimento é a construção dos sujeitos, responsável pelas mudanças de visões, posturas, hábitos, transformação das pessoas a partir de um conhecimento de si e do mundo. De forma consciente, o movimento gay surgiu a partir de uma preocupação com o entendimento do mundo, com a tentativa de esclarecer e dominar os parâmetros de sua organização e de classificação da homossexualidade, e com a demanda de desconstruir as identidades homossexuais cristalizadas em busca de novas possibilidades de vivências mais positivas. Portanto, se a idéia era pensar a organização do mundo e como esse grupo estava sendo explicado e se explicava a partir disso, isso significava pensar a política das identidades, não somente as identidades homossexuais, mas todas as identidades que dizem respeito e se relacionam com ela, seja as identidades de gênero ou aquelas vinculadas à orientação sexual.

Enfim, o que parece alimentar todas essas discussões que organizaram e organizam o movimento gay é a questão da intimidade e sua relação com passado-presente, público-privado e a herança moderna. Portanto, é com base nessas reflexões que este artigo se organiza. Além disso, é importante destacar que ao realizar este trabalho de enfrentamento dos desafios postos na relação entre intimidade e sociedade, os movimentos gays podem ser entendidos como espaços educativos. Afinal, contribuem para elaborar novas formas de conhecimento para além dos seus integrantes e para além da homossexualidade. O res- paldo para essa afirmação está nas palavras de Santos (2001), que entende a educação como todo campo de criação das "subjetividades paradigmáticas", ou seja, local em que o pensamento crítico independente, de transformação emancipatória, pode e deve ocorrer.

\section{Intimidade}

Giddens (1993) e Foucault (1988) são alguns dos autores que demonstram como a nossa sociedade se foi constituindo, desde a modernidade, como uma sociedade de alta reflexividade. Dessa forma, suas principais características são “o caráter 'aberto' da autoidentidade e a natureza reflexiva do corpo" (Giddens, 1993, p. 41). Isso significa dizer que, para os grupos que estão lutando para se libertar de classificações preconceituosas e de identidades cristalizadas, a questão "quem sou eu?" toma uma importância contínua. Serve, sobretudo, para contestar os estereótipos dominantes. Como nos lembra Boaventura Santos, quem questiona sobre sua identidade está questionando o seu lugar no mundo e o lugar dos outros. Essa é uma indagação que interessa ao movimento gay, visto que serve para discutir a questão da identidade sexual. Mas não somente aos homossexuais, já que estamos falando de uma sociedade de alta reflexividade, em que o "eu" é um projeto de auto-reflexão para todos, transformando a interrogação "quem sou eu?" numa preocupação contínua da relação entre passado e presente.

Tratando-se de uma sociedade com essa característica, não é de se estranhar o interesse que a intimidade e seus desdobramentos vêm despertando nas pessoas. Corpo, desejo, erotismo, sexo e amor passaram a ser temas que dizem respeito e revelam a identidade de cada um, mantendo um permanente interesse de todos pela intimidade. Somado a isso, a intimidade traz em si uma força de constante transformação que também seduz, já que são possibilidades reais. É inegável que a intimidade pode ser opressiva, desde que ela se defina "como uma exigência de relação emocional constante" (Giddens, 1993, p. 11). Mas essa não é a única forma de vivência da intimi- 
dade. Ao contrário, ela também pode ser um exercício de democracia, desde que entendida "como uma negociação transacional de vínculos pessoais, estabelecida por iguais" (idem, ibidem). Quando o movimento gay luta por uma sociedade desprovida de preconceitos e discriminações, contra julgamentos desiguais, está entendendo a intimidade como espaço democrático, expressão do eu.

A intimidade é, principalmente, uma questão de comunicação emocional entre os homens e com cada um individualmente, como argumenta Giddens (1993). Assim, o engajamento pessoal e coletivo é constante, abrindo alternativas para modificar o domínio sexual. Apostando nos grupos de reflexão e na difusão dos novos valores, o movimento gay pode ser entendido, com base nessa análise da intimidade, como engajamento pessoal e coletivo. Dessa forma, a intimidade é concebida como um palco de luta política, constituindo-se como projeto de emancipação. Emancipação e autonomia caminham juntas nessa luta, já que a autonomia é o pré-requisito para a elaboração de projetos de emancipação. A aposta é por uma mudança de dentro para fora, uma transformação da intimidade iniciada pela autonomia de seus integrantes para a auto-reflexão. A partir daí são abertas as possibilidades dos projetos de emancipação para além do movimento, ramificando-se para outras instituições. Não se trata apenas de emancipação e autonomia. Como conclusão, pode-se pensar todo esse processo como uma ação para a democracia.

A intimidade e o que ela representa para cada um, individualmente, está presente nas diversas categorias de análise que compõem o quadro de preocupações dos movimentos gays organizados, tais como identidade, diferenças, autonomia, emancipação, liberdade e democracia. Esse debate serve tanto para pensar a sociedade atual e seus parâmetros de construção da intimidade, do desejo e do erotismo, como para desconstruí-los em busca de outros mais democráticos.

O campo de discussão da intimidade e suas possibilidades de transformação abrem uma nova perspectiva: a mudança da nossa herança moderna do autocon- trole. A intimidade sempre foi pensada como reveladora da identidade, e nesse sentido era a sexualidade o que mais importava. Os desejos, os sentimentos, enfim, os componentes da sexualidade representam a nossa maior liberdade e talvez por isso estejam sempre no campo dos segredos, entendidos como nossas maiores riquezas, escondidas a sete chaves. Por isso a grande preocupação na revelação e no interesse pela privacidade dos outros. "A pessoa com a qual fazemos sexo, como diz Jeffrey Weeks (1986), 'importa'. Importa tanto que nossas práticas - as imaginadas e as reais - tornam-se sinônimos de nossa identidade e de nosso gênero" (Britzman, 1996, p. 76).

Como já foi dito anteriormente, o surgimento dos movimentos gays no Brasil foi responsável por uma nova face pública para a homossexualidade, com reflexos para o indivíduo, contribuindo para reforçar o entendimento da sexualidade como propriedade do eu, que pode ser vivida, descoberta, revelada, escondida, interrogada, desenvolvida, enfim, controlada. Como mais um componente de uma sociedade altamente reflexiva, a sexualidade é entendida como uma questão maleável do eu, que une o corpo, a auto-identidade e as normas sociais (Giddens, 1993).

Mas pensar a articulação entre sociedade, intimidade e sexualidade é pensar, principalmente, na relação de poder que organiza essa associação. À luz do pensamento foucaultiano, o poder que se organizou em torno da sexualidade não se caracterizou apenas como repressor. Ele foi capaz de produzir prazer e reação. Nesse sentido, quando o movimento gay se dispõe a pensar a organização dos discursos produzidos pela sociedade para classificar e controlar as práticas homoeróticas, ele está questionando essa relação de poder presente na sexualidade. Mais do que isso, ele está reagindo a essa relação de poder, propondo novas formas de conhecimento que lutam em duas direções: por um lado, combatem e desconstroem os discursos dominantes, e, por outro, elaboram novas formas de entendimento para as práticas homoeróticas.

Assim, o trabalho desenvolvido nos movimentos gays classifica-se no que Boaventura Santos (2001) 
chama de "ciência multicultural", aquela ligada "a novas formas de conhecimento e, igualmente, a novas formas de poder" (p. 7). A nossa herança moderna nos faz pagar um preço: a repressão crescente. Os movimentos gays como espaços educativos nos fazem ter mais atenção para as realidades plurais que compõem a quantidade indeterminada de práticas sociais, culturais e políticas. Trabalhando com novas formas de conhecimento, o movimento gay pode ser entendido como movimento emancipatório, já que parte de um passado que nos prende a formas discriminatórias e excludentes. Nesse sentido, ressalta a exigência de se pensar os nossos problemas. A visibilidade expõe aos olhos de todos os "problemas" que em princípio poderiam parecer apenas de gays, mas que são percebidos como de todos, que muitas vezes passam despercebidos e que se vêm repetindo ao longo dos anos. A visibilidade e a necessidade de se repensar a construção da homossexualidade envolve questões ligadas à justiça, à liberdade, à fraternidade, enfim, lutas que são comuns a vários grupos e povos com realidades locais e lutas muito próprias, e que são resolvidas através da produção de novas formas de conhecimento e poder.

\section{Público e privado}

Quando se discute a transformação da intimidade, pode-se correr o risco de considerá-la essencialmente privada. No entanto, este é um que desperta o interesse público, especialmente no que se refere à sexualidade (Giddens, 1993; Foucault, 1988). Afinal, estamos tratando de uma sociedade altamente reflexiva, que tornou a sexualidade sinônimo de identidade, o que faz com que todos se preocupem constantemente com a intimidade e as identidades dos outros. Portanto, a intimidade é afetada tanto pelo público quanto pelo privado. E, na medida em que a sexualidade foi sendo responsável pela definição das identidades, a intimidade, o desejo e o sexo tornaram-se práticas sociais que servem para criar as diferenças, e não somente as semelhanças. E isso ocorre tanto no aspecto público quanto no privado.
O movimento gay lida com esse conflito: se o que une é o desejo pelo mesmo sexo, esse desejo também serve para diferenciar os homossexuais masculinos dos femininos, dos bissexuais e de outras identidades sexuais. Essas não são questões que dizem respeito apenas ao privado, já que estamos falando de identidades, imagens, classificações, enfim, construções que ocorrem no social, impregnadas de cultura e história. Assim, o privado foi fortalecendo-se como domínio do segredo, da psique, do que é "autêntico" porque diz respeito aos nossos sentimentos, o que está ou deveria estar guardado a "sete chaves" e o que revela quem somos, nossas identidades. Portanto, pensar o movimento gay pela perspectiva do privado e do público significa refletir sobre sentimentos, identidades, diferenças que são construídas no social, coletivo e cultural. Como defende Giddens (1993), a intimidade representa um potencial de liberdade.

Não obstante, a psique é tratada como se tivesse uma vida interior própria. Considera-se esta vida psíquica tão preciosa e tão delicada que fenecerá se for exposta às duras realidades do mundo social e que só poderá florescer na medida em que for protegida e isolada. $\mathrm{O}$ eu de cada pessoa tornou-se o seu próprio fardo; conhecer-se a si mesmo tornou-se antes uma finalidade do que um meio através do qual se conhece o mundo. E precisamente porque estamos tão absortos em nós mesmos, é-nos extremamente difícil chegar a um princípio privado, dar qualquer explicação clara para nós mesmos ou para os outros daquilo que são as nossas personalidades. A razão está em que, quanto mais privatizada é a psique, menos estimulada ela será e tanto mais nos será difícil sentir ou exprimir sentimentos. (Sennett, 1988, p. 16)

Para Sennett, "as relações civilizadas entre os indivíduos só podem ter continuidade na medida em que os desagradáveis segredos do desejo, da cobiça ou inveja forem mantidos a sete chaves" (idem, p. 17). É o paradoxo da visibilidade e do isolamento: na medida em que todos se vigiam, em que há um interesse pela intimidade como revelação da identidade, diminui a sociabilidade, e o silêncio passa a ser a única 
forma de proteção. Daí a necessidade das pessoas de terem um local específico, em público, para se reunirem e ao mesmo tempo manterem certa distância da observação íntima dos outros, para se socializarem e para sentirem-se em grupo. $\mathrm{O}$ espaço do movimento gay é um exemplo dessa necessidade. As reuniões entre os integrantes favorecem uma sociabilidade diferente quando estão na presença de outras pessoas.

No entanto, a luta do movimento gay por visibilidade parece ir em direção ao rompimento desse paradoxo da visibilidade e do isolamento apontado por Sennett. A luta por visibilidade do movimento gay define-se também pelo fim do silêncio e pelo alastramento das práticas homoeróticas para além dos "guetos" gays. Isso não significa a negação dos espaços específicos, como boates, saunas e as sedes dos movimentos gays, mas a defesa de que as práticas homoeróticas não deveriam ficar confinadas a esses locais. No entanto, esta defesa está embasada na necessidade da construção de identidades mais valorizadas que reflitam numa auto-estima positiva dos homossexuais. Somente a partir desse pressuposto será possível romper com a necessidade de espaços específicos, proporcionando um aumento da sociabilidade.

Ao contrário da análise de Sennett, o movimento gay não percebe a visibilidade, a revelação da intimidade e da identidade gay como diminuição da sociabilidade; tampouco entende o silêncio como proteção, embora ainda hoje muitos gays compreendam suas identidades homossexuais dessa forma, ou seja, somente mantendo sua intimidade como gays em segredo poderão manter a sociabilidade ou a "aceitação social” ideal, e aí o silêncio é entendido como proteção. Por isso, quando o movimento gay luta por visibilidade através da política do "sair do armário", está lutando contra a organização da cultura e de nossa herança moderna de uma sociedade vigilante e classificadora da sexualidade.

A busca é por uma nova forma de pensar a sociedade, pela necessidade de pensar o político, nossas práticas cotidianas e a vida pública de outra forma. O movimento gay, nesse sentido, lida com uma concepção de político como ruptura com o passado, do que é entendido como "dado", automático e previsível. Como defende Hannah Arendt, as ações políticas alastram-se a todas as práticas humanas, desde as mínimas até as mais complexas. Dessa forma, as ações políticas referem-se a todos os espaços públicos, o que nos ajuda a pensar o movimento gay como importante espaço público educativo, já que por meio dele podem e devem ser criados e recriados o cotidiano, as ações humanas e os espaços, de forma permanente.

Arendt, assim como Foucault, defende que a identidade não é algo dado, mas está em permanente construção e realiza-se nos variados espaços públicos por onde os indivíduos circulam, negociam e renegociam com os outros. Essa definição também nos serve para uma melhor compreensão sobre a importância do movimento gay não apenas como espaço de negociação, de definição e redefinição das identidades homossexuais, ressaltando a importância e a necessidade do alastramento desses espaços, através de suas discussões, para outros menos democráticos com as diferenças sexuais.

Para Sennett (1988), é duplo o problema público da sociedade contemporânea: os comportamentos e as soluções impessoais não despertam paixão, fato que só ocorre quando se trata de questões que envolvem personalidade. Com base nesse raciocínio, é possível entender o interesse pela intimidade, visto que ela foi construída diretamente relacionada à personalidade. Este é um aspecto importante que afeta o movimento gay. As discussões causam grande paixão nos seus integrantes quando estão em pauta aspectos que dizem respeito à personalidade, à identidade, como por exemplo quando se discute fidelidade, promiscuidade, entre outros assuntos que possibilitam trazer a experiência para a reflexão, misturando os temas com as identidades e vivências individuais. Quando se propõem discussões mais impessoais, como a representatividade no legislativo como condição para a defesa de questões que interessam ao movimento, o entusiasmo é menor e rapidamente ocorre a fuga ao tema nas reuniões, e a discussão descamba para outros assuntos fora do foco inicial. 
Quando as pessoas perdem interesse pelo mundo público, quando não há um envolvimento pessoal e quando a vida pública se torna questão de obrigação formal, enfim, quando há uma deformação da vida pública, isso também afeta as relações íntimas, a vida privada, que passa a despertar o interesse das pessoas. Segundo Sennett (1988), o amor físico é o que, nestas quatro gerações, ${ }^{4}$ pode ser o maior exemplo desse duplo problema da sociedade contemporânea, traduzido nas alterações da vida pública e seu desdobramento na erosão da vida privada.

Sendo assim, a luta do movimento gay articulase em torno do grande problema da nossa sociedade, ou seja, uma vida pessoal desmedida e um interesse pela vida pública esvaziada. Na verdade, a luta é por uma união entre vida privada e pública, capaz de entender a relação existente entre elas, direcionando o interesse para questões públicas, entendendo-as como políticas que dizem respeito a um universo de relações sociais. O movimento gay luta por inserir o entendimento da homossexualidade numa perspectiva política, e não exclusivamente social e sexual. O desafio, portanto, é associar as discussões do campo privado com o público.

\section{Passado-presente}

A utilização da metáfora do casebre serve perfeitamente para perceber a importância da relação passado-presente na construção da homossexualidade. Pode-se indagar a respeito do poder do passado na organização da intimidade e, especificamente, no que se refere às identidades homoeróticas. Qual o papel educativo dos movimentos gays na destruição desse case-

${ }^{4}$ Embora Sennett (1988) não defina claramente datas quando se refere "as quatro gerações", ele utiliza o termo para localizar o leitor num tempo definido, ou seja, nas transformações ocorridas na passagem do século XIX para o XX, em que o amor físico se foi afastando, cada vez mais, do erotismo vitoriano que envolvia relacionamentos sociais para se aproximar da sexualidade e sua relação com a identidade pessoal. bre e na limpeza do terreno para a construção de novas bases para uma residência sólida que abrigue a variedade de práticas homoeróticas? Quando o movimento gay conduz a questão da identidade homossexual utilizando como exemplo as palavras "destruir", "construir" e "limpar", está entendendo esse processo como parte de uma construção social, histórica e cultural, possibilitando pensar num projeto de emancipação.

Como afirma Santos (1997, p.103): "Vivemos um tempo sem fulgurações, um tempo de repetição".

"A idéia da repetição é o que permite ao presente alastrar-se ao passado e ao futuro, canibalizandoos" (idem, ibidem). Para o autor, fica difícil pensar a transformação social e a emancipação enquanto estivermos presos ao passado, enquanto não reinventarmos o passado. $\mathrm{O}$ passado deveria servir como fonte geradora de inconformismos. O pensamento do passado é o pensamento das raízes, ou seja, aquele que é "profundo, permanente, único e singular, tudo aquilo que dá segurança e consistência [...]"; enquanto o pensamento do futuro é o "pensamento das opções, [...] aquilo que é variável, efêmero, substituível, possível e indeterminado a partir das raízes" (Santos, 1997, p. 106).

$\mathrm{O}$ entendimento do cotidiano, das identidades e das diferenças como construção social, histórica e cultural parece contribuir para a elaboração de projetos de emancipação, que serão construídos no presente a partir dos inconformismos do passado e com a perspectiva do pensamento das opções, do futuro. Seguindo esse raciocínio, pode-se concluir que os movimentos gays, entendidos como local de questionamento, de construção de conhecimento, deveriam, a partir do pensamento do passado, das raízes, propiciar a elaboração de perspectivas para um pensamento do futuro, das opções. Para Santos (1997), raízes e opções não se opõem, mas se complementam. A transformação da realidade, a construção das identidades e o projeto de emancipação dos grupos estão relacionados com o equilíbrio entre raízes e opções. Em determinados momentos históricos, e para alguns grupos sociais, as raízes predominam sobre as opções ou vice-versa. 
Sem o páthos da tensão entre raízes e opções não é possível pensar a transformação social, mas tal impossibilidade perde grande parte do seu dramatismo se a transformação social, além de impensável, é julgada desnecessária. Esta ambigüidade conduz ao apaziguamento intelectual, e este, ao conformismo e à passividade. Há, pois, que recuperar a capacidade de espanto e de construí-la de modo a poder traduzir-se facilmente em inconformismo e rebeldia. (Santos, 1997, p. 116)

O passado e suas teorias devem ser pensados como iniciativa humana, e não como algo dado. Somente dessa forma será possível construir interrogações e posições inesgotáveis a partir deles. Assim sendo, diminui-se o conformismo com o que é aceito só porque existe, recuperando-se a capacidade do espanto, de desconstrução e de emancipação dos indivíduos e dos grupos diante das posições de força.

O que se defende, portanto, é a necessidade de se entender a construção das identidades como a possibilidade de elaboração de um projeto de emancipação que contribua para a transformação social. Partindo do princípio de que as identidades são resultados transitórios e fugazes de processos de identificação permanentemente em construção e transformação, Santos (1993) defende a idéia de identidade como sendo identificações em curso e, por isso, sempre sujeitas às negociações de sentido e temporalidade.

Santos (1993) ainda chama a atenção para a existência de uma crise de regulação que cria, por conseguinte, uma crise de emancipação, afetando diretamente a relação dos grupos e as identidades. O que falta é um pensamento estratégico de emancipação, verdadeiramente original, prejudicado pelo processo de descontextualização e universalização das identidades. Esse processo contribuiu para que as classes dominantes elaborassem projetos universais e globais de emancipação, e as minorias tentavam enquadrar-se nesses projetos globais legitimados socialmente, fazendo com que ainda hoje (e o autor denuncia isso) as classes sociais e as negociações de identidades tendam mais a pensar em projetos táticos do que estratégicos de emancipação. Portanto, para ele, essa crise de emancipação é, sobretudo, uma crise dos sujeitos sociais. Então, para pensar a emancipação e a transformação social das identidades oprimidas, é necessário recuperar o passado como fonte de inconformismos.

Assim, para que essa situação se altere em favor da constituição de sujeitos sociais emancipatórios, é preciso entender a construção das identidades sempre como o espaço onde se desenvolvem as relações sociais antagônicas, fazendo surgir, aos olhos de quem interroga sobre sua identidade, seus inimigos.

Entretanto, a solução dessa equação - e, por conseguinte, a emancipação política - não está à disposição de todos. Ao contrário, as mesmas raízes podem, para uns, fornecer novas opções e, para outros, negar. É preciso voltar ao passado, impulsionado pelo inconformismo e pela raiva, entendendo-o como produto da construção humana e, a partir daí, colocar interrogações e tomadas de posição em relação a ele, ao presente e ao futuro. $\mathrm{O}$ ideal para a emancipação das identidades é que se compartilhe dessas interrogações e não das suas respostas, trazendo as questões à tona para que se possam pensar as opções sem ficar preso às raízes. Esta parece ser uma contribuição importante do movimento gay: ampliar as discussões para além do movimento, compartilhando as questões.

\section{Considerações finais}

A lógica da organização das reuniões do Movimento Gay de Minas (MGM) serve para entender como a nossa sociedade se organiza no que se refere ao sexo. Ela revela a preocupação e a existência, em nossa sociedade, de um discurso sobre o desejo e tudo que se refere a ele. Isso porque expor os desejos, os interesses e as atrações parece definir e revelar as identidades. A revelação dos desejos aproxima-se da verdade, da identidade. Isso demonstra como a herança moderna está mais presente nas nossas ações e pensamentos do que supomos, como bem nos lembra Foucault (1988).

Na verdade, a revelação é presente no espaço 
do movimento gay porque ela vem entendida pelos seus membros ainda com a perspectiva que a modernidade lhe conferiu, ou seja, como condição de viver "sem máscaras". Além disso, a prática da revelação vem fortalecida por outros aspectos que devem ser considerados. Primeiro é a vivência, durante algum tempo, da obrigação de silenciar os desejos, entendidos como proibidos, errados, anormais, enfim, que deveriam ser escondidos. Nesse sentido, o movimento gay constitui-se como espaço onde podem falar de tudo que sempre tiveram vontade, sem medos, é o espaço da libertação, da liberdade. Podem revelar o que gostam, o que sentem e o que querem. Segundo, que essa possibilidade de colocar para fora o que estava preso concede aos membros um sentimento de emancipação, de vitória diante da repressão. Assim, o movimento gay também passa a ser o espaço da emancipação. Por esses dois aspectos, o movimento gay caracteriza-se pela inversão da lei do mundo, em que as verdades devem ser escondidas (Foucault, 1988). É o prenúncio de um dia em que todos poderão assumir no cotidiano, da mesma forma que fizeram no espaço do movimento gay. Esse é o sentimento e a luta que predomina nas reuniões, é o anúncio de dias novos, uma proposta para o futuro, a promessa de felicidade.

A presença da herança do Ocidente moderno está organizada por duas vias: uma é a luta para romper com essa herança, que ainda mantém a sexualidade no campo da produção dos discursos; a outra é o predomínio da revelação quando se fala da sexualidade, entendendo-a como intimamente ligada à identidade dos sujeitos. Em ambos os casos, o que se busca é a produção e/ou confissão da verdade, o que traz à tona a relação com o poder.

Em princípio, a presença dessa herança pode ser lida pela vigência do silêncio que ainda vigora quando se discute sexualidade e, principalmente, as sexualidades marginalizadas. $\mathrm{O}$ alerta de Foucault renovase: ainda hoje vivemos os reflexos do regime vitoriano, caracterizado pela "nossa sexualidade contida, muda e hipócrita” (1988, p. 9). A partir do século XIX, a sexualidade passa para o interior das casas, como algo particular, de responsabilidade das famílias, que passam a se dedicar e a se preocupar, cada vez mais, com a sua manutenção e com a ordem sexual. O casamento e suas ameaças, a reprodução, a educação das crianças, a sexualidade sadia em oposição as transgressões passam a ser a preocupação da família conjugal e do Estado. E essa preocupação se transforma, gradativamente, em discurso entendido como produção de verdade.

Em contrapartida, essa mesma família conjugal se cala diante do sexo, do desejo, do erotismo, enfim, de tudo que está ligado às paixões, entendidas como capazes de desestruturar as pessoas e que, portanto, deveriam ser evitadas. A sexualidade passa a ser contida, desprovida de paixão, prazer e desejo, mas direcionada para a saúde, a ordem e a reprodução. Os desejos deveriam ser renunciados e reprimidos pelos homens. O século XIX organiza e vai organizando-se com base nessas idéias, ditando o que pode e o que não pode ser feito, vivido, definindo o "normal" e o "anormal", distinguindo o "certo" do "errado".

O que não é aceito é reservado ao silêncio. Assim acontece com as práticas homoeróticas, expulsas, negadas, proibidas e silenciadas. A qualquer tentativa de manifestação, seja como fato ou como assunto, são perseguidas na intenção de fazê-las desaparecer. No entanto, esse afã de identificar, silenciar, vigiar, punir, caçar e evitar as formas de sexualidade "marginalizadas" teve um resultado inverso, uma produção cada vez maior de discursos. O século XIX não foi capaz de realizar seu objetivo. Mesmo porque a repressão causa uma reação que, como a primeira, também está ligada ao poder e ao prazer, visto que ela cria a norma e, por consequiência, a possibilidade de transgressão.

Lidar com essa relação entre repressão e resistências, entendidas como produção de poder e prazer, está na pauta de discussão dos movimentos gays, por mais que não se dêem conta disso. E o desafio que se coloca para o movimento gay é o de produzir uma “nova economia dos mecanismos de poder", ligada à restituição do prazer, como ressalta Foucault (1988). Quando o movimento gay parte de um incômodo com 
o passado, com a produção de "verdades" sobre as homossexualidades, lutando pelo direito de expressão do amor e do desejo homossexual, está reescrevendo as formas de prazer. Na verdade, está utilizando a mesma lógica que dominou e censurou a homossexualidade, ou seja, está produzindo discurso, construindo "verdades" condicionadas ao poder. A análise de Foucault, neste sentido, é uma possibilidade de leitura dessa relação entre repressão e resistência e, portanto, do trabalho do movimento gay.

Por essa perspectiva, o movimento gay passou a constituir-se como um espaço de luta política, diferente de outros lugares onde as sexualidades marginalizadas eram permitidas no século XIX. Se é inegável que as sexualidades marginalizadas foram perseguidas e proibidas do convívio das famílias e dos espaços privados, elas foram permitidas em lugares específicos, em que não produziam conhecimento, mas lucro, como os cabarés e as casas de saúde, por exemplo. Ainda hoje os espaços de sociabilidade e vivências da homossexualidade, como boates, saunas, cinemas e bares articulam-se nessa lógica de espaços de permissão, longe das famílias, voltados para o lucro, distantes da produção de conhecimento. $\mathrm{O}$ espaço do movimento gay constitui-se como a exceção: embora mantendo essa característica de espaço de permissão, vem constituindo-se cada vez mais como espaço de produção de conhecimento e lutando para se expandir para além de suas paredes, atingindo o espaço e o debate público e constituindo-se como local de luta política, lutando para romper com a herança ocidental moderna.

O trabalho do movimento gay constitui-se essencialmente no que Foucault classifica como causa política, quando trata do discurso produzido sobre sexo, sexualidade, desejo, verdade, ou seja, com os reflexos da nossa herança moderna. Ao falar de homossexualidade e relacioná-la à defesa do direito por prazer, amor, desejo, o movimento gay insere-se nessa causa política. Para Foucault (1988), a causa do sexo, quando se liga à produção de conhecimento e ao direito de falar dele, está associada à liberdade, aproximando-se da teoria da emancipação defendida por
Boaventura Santos. Tanto as idéias de Foucault quanto as de Boaventura Santos se aproximam, já que ambas se inscrevem numa perspectiva de futuro.

Uma vez que nossa herança colocou a homossexualidade no campo do proibido, falar dela, defendêla, produzir conhecimento ao seu redor, lutar por sua visibilidade, possui um aspecto de transgressão. Segundo Foucault (1988), quem defende esse discurso se posiciona, de certo modo, fora do alcance do poder, visto que desestrutura a lei e antecipa a liberdade futura. O movimento gay lida com essa liberdade futura o tempo todo, na sua luta por uma construção de uma sociedade mais justa. Os membros do movimento gay parecem ter consciência dessa preparação para a liberdade futura, que está baseada num processo educacional capaz de construir identidades mais valorizadas da homossexualidade, tanto para seus membros quanto para o grande público, mesmo porque isso só poderá ser construído pelo diálogo, pelo confronto e pela negociação com a sociedade mais abrangente. É, ao mesmo tempo, a consciência de desafiar a "ordem estabelecida", negando o passado na mesma perspectiva de Boaventura Santos, de se incomodar com esse passado visando construir algo novo sobre suas estruturas. Como bem falou o dirigente do MGM, destruir o casebre, limpar o terreno e só então erguer o prédio.

ANDERSON FERRARI, mestre em educação pela Universidade Federal de Juiz de Fora e doutorando em Educação na UNICAMP, é professor do Colégio de Aplicação João XIII da UFJF e participante do Grupo de Estudos Interdisciplinares em Sexualidade Humana, da UNICAMP. Publicou: Contribuições teóricas para educação a partir do homoerotismo masculino. In: SANTOS, Rick, GARCIA, Wilton. A escrita de Adé: perspectivas teóricas dos estudos gays e lésbic@s no Brasil (São Paulo: Xamã \& NCC/SUNY, 2002); Diferença, igualdade e formação de identidade no contexto escolar. Instrumento: Revista de Estudo e Pesquisa em Educação, v. 2, n 1, EdUFJF, 2000; O “império” do livro didático no imaginário dos professores de história. Instrumento: Revista de Estudo e Pesquisa em Educação, v. 3, no 1, EdUFJF, 2001. Projeto atual de pesquisa no doutorado: Educação e movimentos gays.E-mail: aferrari@artnet.com.br 


\section{Referências bibliográficas}

BRITZMAN, Deborah P., (1996). O que é esta coisa chamada amor, identidade homossexual, educação e currículo. Educação \& Realidade, Porto Alegre, UFRGS, v. 21, nº 1 p. 71-96, jan.-jun.

FOUCAULT, Michel, (1988). História da sexualidade I: a vontade de saber. Rio de Janeiro: Graal.

FRY, P., MACRAE, Edward, (1985). O que é homossexualidade. São Paulo: Brasiliense.

GIDDENS, Anthony, (1993). A transformação da intimidade: sexualidade, amor \& erotismo nas sociedades modernas. São Paulo: Editora UNESP.

GREEN, James Naylor, (2000). Além do carnaval: a homossexualidade masculina no Brasil do século XX. São Paulo: Editora UNESP.

MACRAE, Edward, (1990). A construção da igualdade: identidade sexual e política no Brasil da abertura. Campinas: Editora da UNICAMP.
OLIVEIRA, Ivone M. de, (1994). Preconceito e autoconceito: identidade e interação na sala de aula. Campinas: Papirus.

SANTOS, Boaventura de Souza, (1993). Modernidade, identidade e a cultura de fronteira. Tempo Social, São Paulo, v. 5, $\mathrm{n}^{\circ} 1$ 2, p. 31-52.

(1997). A queda do Ângelus Novus; para além da equação moderna entre raízes e opções. Novos Estudos CEBRAP, São Paulo, nº 47, p. 103-124.

, (2001). Dilemas do nosso tempo: globalização, multiculturalismo e conhecimento. Entrevista. Educação \& Realidade, Porto Alegre, UFRGS, v. 26, n 1, p. 13-32.

(org.), (2002). Democratizar a democracia: os caminhos da democracia participativa. Rio de Janeiro: Civilização Brasileira.

SENNETT, Richard, (1988). O declínio do homem público: as tiranias da intimidade. São Paulo: Companhia das Letras.

Recebido em setembro de 2003 Aprovado em novembro de 2003 